\title{
Anisotropic radio-wave scattering from englacial water regimes, Mýrdalsjökull, Iceland
}

\author{
Kenichi MATSUOKA, ${ }^{1}$ Throstur THORSTEINSSON, ${ }^{1,2}$ Helgi BJÖRNSSON, ${ }^{2}$ \\ Edwin D. WADDINGTON ${ }^{1}$ \\ ${ }^{1}$ Department of Earth and Space Sciences, Box 351310, University of Washington, Seattle, Washington 98195-1310, USA \\ E-mail: matsuoka@ess.washington.edu \\ ${ }^{2}$ Institute of Earth Sciences, University of Iceland, Sturlugata 7, IS-101 Reykjavík, Iceland
}

\begin{abstract}
Colinear-polarized $5 \mathrm{MHz}$ radar profiling data were obtained on Mýrdalsjökull, a temperate glacier in Iceland. Radar transects, and therefore polarization planes, were aligned approximately parallel, transverse and oblique to the ice flow direction. Echoes from the shallower half to two-thirds of the ice were 10-20 dB stronger on the oblique and longitudinal transects than those on the transverse transects. Anisotropy as a function of depth is clearly seen at the sites where the transects cross. Strong scattering on longitudinal transects apparently caused extinction of a radar-reflecting layer that was continuously profiled on the transverse transects. A radio-wave scattering model shows that scattering from a longitudinal water-filled conduit parallel to the glacier surface can explain the observed azimuthal variations of the echo. We conclude that low-frequency $(\sim \mathrm{MHz})$ radio waves can help to characterize englacial water regimes.
\end{abstract}

\section{INTRODUCTION}

Water passageways introduce heterogeneity to the interior of temperate glaciers. They route rain and surface meltwater efficiently into and beneath the body of the glacier. Basal water, in turn, strongly controls basal motion of the glacier. Macroscopic ice-walled near-circular conduits are generally considered to provide passageways for water through glaciers (Shreve, 1972; Fountain and Walder, 1998). Recently, Fountain and others (2005) proposed that the primary passageways are provided by fractures, rather than pipe-like conduits. Characteristics of these water passageways and their seasonal evolution and spatial variations are keys to understanding the hydrology and dynamics of mountain glaciers. Acceleration of polar glaciers following increased surface melting is caused by increased basal motion, which is presumably caused by penetration of surface meltwater to the bed (Zwally and others, 2002). Understanding the geometry of water passageways is crucial if we want to examine spatio-temporal relationships between surface melting and basal lubrication events and, ultimately, assess the response of ice sheets to climate change. Radar is the unique tool to determine the evolving geometry and distribution of water passageways.

The strong contrast in dielectric permittivity between ice and water facilitates radio-wave remote sensing as a viable method to investigate spatio-temporal variations of glacier interiors. Frequency dependence of the radio echoes has been used to map thermal regimes of polythermal glaciers (Bamber, 1987; Björnsson and others, 1996; Moore and others, 1999; Pettersson, 2005) and water cavities in a temperate glacier (Jacobel and Raymond, 1984). In addition, radar polarization can potentially be used to characterize englacial water regimes. As water bodies have curved shapes, regardless of whether they are fractures or conduits, they can depolarize radio waves.

At a polythermal glacier, Storglaciären, Sweden, Walford and others (1986) found that echoes from within temperate ice varied with the radar polarization. Using $60 \mathrm{MHz}$ co-polarized waves they made measurements with two polarizations, one aligned approximately parallel to the ice flow, the other approximately perpendicular. Polarization parallel to the ice flow gave, on average, $15 \%(0.7 \mathrm{~dB})$ stronger echoes at a given depth than polarization perpendicular to the ice flow. They suggested that this feature was caused by water-filled cavities and, to a lesser extent, air-filled cavities.

That study leads us to hypothesize that englacial water passageways make azimuthal variations in the radio echo at low frequencies $(\sim \mathrm{MHz})$ in terms of the radar polarization. Radio waves of $1-10 \mathrm{MHz}$ are more commonly used than those of higher frequencies to examine temperate glaciers because of their greater penetration through heterogeneous temperate ice. Our objective is to test this hypothesis with field observations using $5 \mathrm{MHz}$ radar, which we augmented with numerical results for scattering from a cylinder. We established transects at a range of orientations on Mýrdalsjökull, a temperate glacier in Iceland. We compared the englacial echo intensity as a function of polarization and depth at the crossover sites of these transects to look for polarization dependence.

\section{RADAR MEASUREMENTS}

Radio-echo intensities were recorded along thirteen transects over a $4 \mathrm{~km} \times 4 \mathrm{~km}$ area (Fig. 1a) on northern Mýrdalsjökull; six transects were approximately parallel to, and five transects were approximately transverse to, the estimated ice flow direction (i.e. local steepest-descent path on the surface). Two additional transects had intermediate oblique orientations (Fig. 1b). These transects were profiled within a 3 day period in April 2003. Ice thickness in this area, derived from these radar data, is shown in Figure 1c (after Thorsteinsson and others, 2005). The equilibrium-line altitude (ELA) on the northern slope of Mýrdalsjökull is estimated to be $1000 \mathrm{~m}$ a.s.l. (Brandt and others, 2005). During our measurements, the glacier surface was covered by approximately $7 \mathrm{~m}$ of seasonal snow; this depth was estimated while a steam drill was used to install poles for an ice-motion study 
a
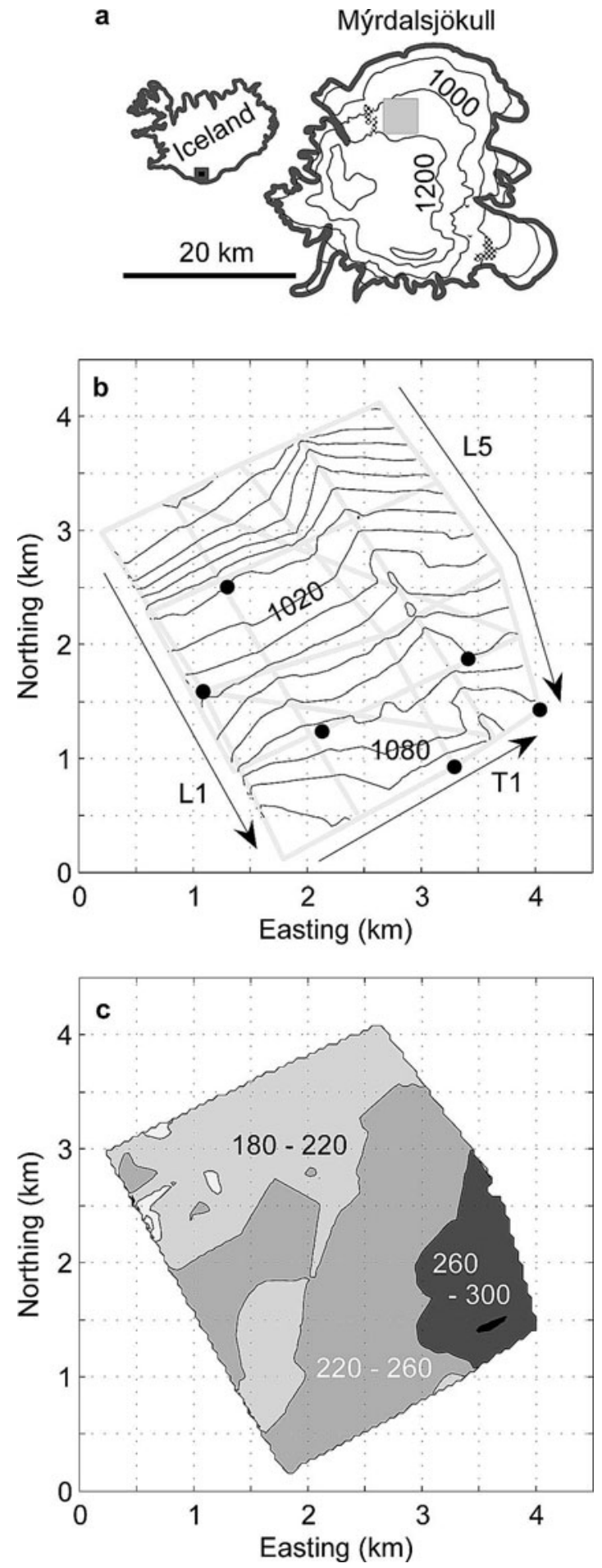

Fig. 1. (a) Mýrdalsjökull, south Iceland. The shaded rectangle on northern Mýrdalsjökull shows our study area. Contour lines on Mýrdalsjökull show the surface elevation with $200 \mathrm{~m}$ intervals, and hatched areas indicate nunataks (Björnsson and others, 2000). (b) The 13 radar transects (gray lines) in the $4 \mathrm{~km} \times 4 \mathrm{~km}$ study area. Origin of this local coordinate system is Universal Transverse Mercator (UTM) coordinate $5.91 \times 10^{5}$ easting and $7.068 \times 10^{6}$ northing in zone $28 \mathrm{~N}$. Contour lines show glacier surface elevation (Thorsteinsson and others, 2005). Six solid circles represent GPS stations where ice flow velocities were measured. Ice flows approximately toward north-northwest. Longitudinal transects are named L1-L5 from west to east. Transverse transects are named T1-T5 from high elevation to low elevation. Radargrams along L1, $\mathrm{T} 1$ and L5 transects are shown in Figure 2. (c) Ice thickness over the study area (Thorsteinsson and others, 2005). Ranges of $40 \mathrm{~m}$ are shown on a grayscale numbers in each band give the maximum and minimum thicknesses in that range. using a global positioning system (GPS) (personal communication from S. O'Neel, 2004). All snow would be gone before the following September. Displacements measured by GPS at six sites (Fig. 1b) between April and September gave summer ice flow speeds of $30-54 \mathrm{~m} \mathrm{a}^{-1}$ in this area (Thorsteinsson and others, 2005).

We employed a short-pulse radar system that has been successfully used to evaluate echo intensities from the bed in Antarctica (Gades and others, 2000; Catania and others, 2003). We used resistively loaded half-wavelength dipole antennas, resonant at $5 \mathrm{MHz}$. We set colinear transmitting and receiving antennas in line on the snow so the radarpolarization plane was always aligned along the radar transects. We used a field effect transistor switch in the transmitter to produce pulse amplitudes far more stable than transmitters with an avalanche transistor switch (Weertman, 1993; Matsuoka and others, 2004). The stability is critical for echo-intensity evaluation.

Radio echoes were stacked and bandpass-filtered with band limits of $\pm 2 \mathrm{MHz}$ from the center frequency of $5 \mathrm{MHz}$. Given stable radar system characteristics, we represent the internal reflection power (IRP) as the averaged square of induced voltage, $V$, in the receiving antenna integrated over a finite time window (Gades and others, 2000) such that

$$
\mathrm{IRP}=\frac{1}{t_{2}-t_{1}} \int_{t_{1}}^{t_{2}} V^{2}(t) \mathrm{d} t .
$$

The time-window width, $t_{2}-t_{1}$, is arbitrary, but it must be longer than $0.34 \mu \mathrm{s}$, the period of a wave of frequency $3 \mathrm{MHz}$, the lower cut-off frequency of the bandpass filter.

\section{RESULTS}

Radio echoes along three of the thirteen transects are shown in Figure 2. We found a continuous 'radar-reflecting layer' whose depths are consistent at the radar-transect crossover sites. However, the layer is much clearer along T1 than along L5 at their crossover site. The layer was tracked with a semi-automatic routine that was guided manually to find the largest and smallest voltage levels associated with the layer within a certain depth range. Figure 3 shows the depth of that layer; the layer is not well recognized along most of L3, L4 and L5. This is because the radar reflections from the layer are co-temporal with other scattering, causing the layer-tracking routine to produce less spatially consistent layer depths. The layer is seen clearly in roughly the western upstream quadrant of the study area, regardless of the azimuth of the transects. In the eastern upstream quadrant, the layer is seen continuously along transverse transects. Depths of the radar-reflecting layer are consistent at radartrack crossover sites wherever the layer is visible on both transects. Thus, it is likely that the layer is continuous over the southern (upstream) half of the study area, but other scattering masks the layer at eastern locations. The reflection probably arises from tephra rather than from the water table. Similar radar-reflecting layers are often seen in Icelandic glaciers (Brandt and others, 2005).

Radar cannot detect any clear echo shallower than $\sim 20 \mathrm{~m}$, because echoes are mixed up with direct waves from the transmitter. Englacial scattering in the downstream half is not as large as that which masks the layer in the upstream eastern quadrant (see below), so the layer will be visible if it exists deeper than $20 \mathrm{~m}$. Thus, in the downstream area less than $\sim 1040$ ma.s.l., the layer either exists at depths 


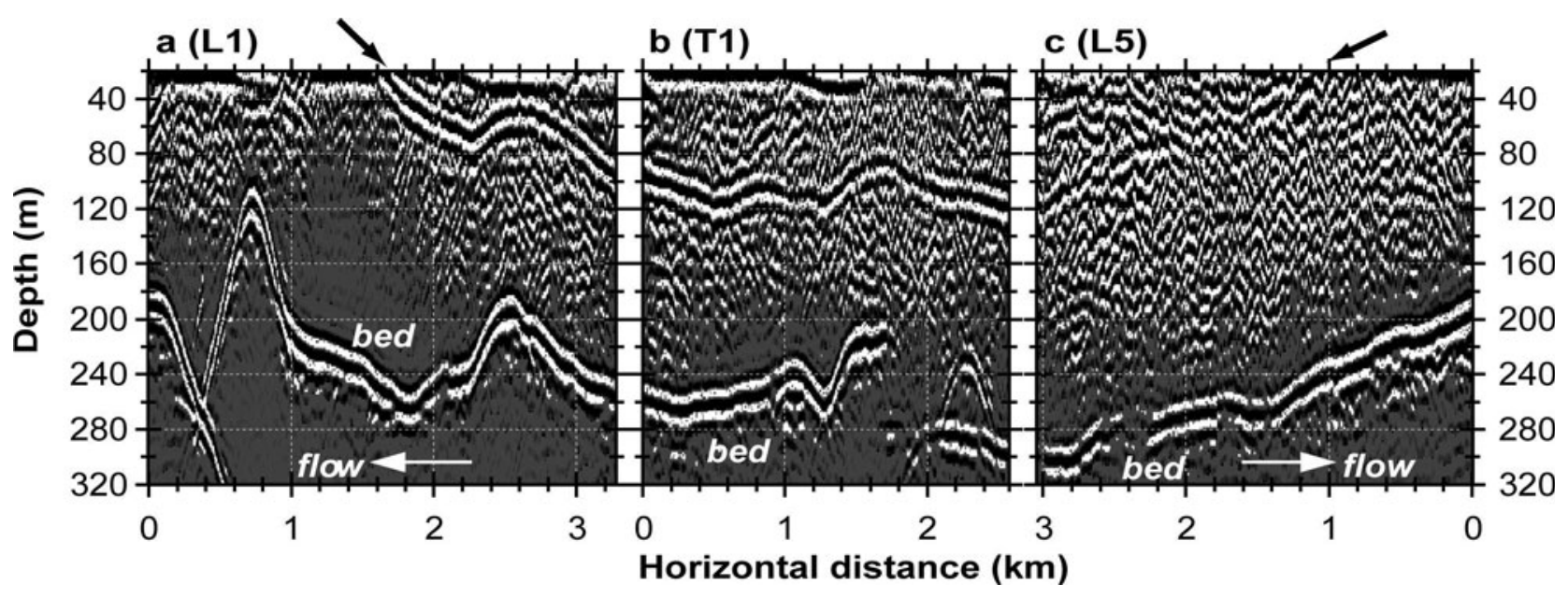

Fig. 2. Radargrams along the three transects labeled in Figure 1. An identical grayscale is used for all radargrams. Vertical exaggeration is $\times 10$. (a) Longitudinal transect L1. The arrow indicates a continuous radar-reflecting layer. (b) Transverse transect T1. (c) Longitudinal transect L5. The arrow indicates the radar-reflecting layer, which is too indistinct along L5 to be continuously tracked by a semi-automatic routine (Fig. 3). Left end of (b) coincides with right end of (a), and left end of (c) coincides with the right end of (b).

shallower than $20 \mathrm{~m}$ or disappears. The long-term ELA in this area is about $1000 \mathrm{ma.s.l}$. and the furthest downstream quarter of our study area is in the ablation zone. In that area, the layer was exposed on the snow surface in the past and most of the tephra was presumably washed out. Therefore, it is likely that the layer gets gradually shallower as it goes downstream until it intersects the summer surface and then disappears in the ablation zone.

We characterize the horizontal variation in scattering from each ice column by calculating the average IRP over the full ice thickness (I IRP hereafter). The englacial radar data record englacial scattering, reflection from the layer (Fig. 3) and hyperbolic or linear reflections from off-nadir bed and sedimentary regimes near the bed (e.g. at $2.4 \mathrm{~km}$ along T1; Fig. 2b), all of which affect $\overline{I R P}$ values. We tested several methods for calculating $\overline{\mathrm{IRP}}$. First, we derived $\overline{\mathrm{IRP}}$ over a single delay-time range between just after the direct wave and just before the continuous bed echo. Then we excluded certain time windows associated with the radar-reflecting layer and some deep hyperbolas. These trials showed that spatial pattern and magnitudes of $\overline{\mathrm{IRP}}$ were insensitive to details of this data reduction, so effects of the layer echoes and hyperbola echoes on IRP are small. Thus, we can use $\overline{\mathrm{IRP}}$ as a proxy for englacial scattering.

We divided calculated $\overline{\mathrm{IRP}}$ by the mean $\overline{\mathrm{IRP}}$ for all transects. This standardized measure, $\overline{\mathrm{IRP}}_{\mathrm{s}}$, along all radar transects is shown in Figure 4. $\overline{\mathrm{IRP}}_{\mathrm{s}}$ varies significantly along transects. In addition, values of $\overline{\mathrm{IRP}}_{\mathrm{S}}$ on intersecting transects differ significantly at six radar-transect crossover sites, labeled A-F (Table 1). Differences in $\overline{\mathrm{IRP}}_{\mathrm{s}}$ values between the oblique and longitudinal transects are less than $1 \mathrm{~dB}$, while $\overline{\operatorname{IRP}}_{\mathrm{s}}$ values on the transverse transects are $4-17 \mathrm{~dB}$ smaller than those along the longitudinal transects. This variation with azimuth at sites $\mathrm{A}-\mathrm{F}$ is as large as horizontal variations of $\overline{\mathrm{IRP}}_{\mathrm{s}}$ values over the study area.

Depth variations of IRP were calculated at sites A-F. The time-window width, $t_{2}-t_{1}$, was set to $0.34 \mu \mathrm{s}$ in Equation (1). The time window was moved from shallow to deep to derive depth variations of IRP $\left(\operatorname{IRP}_{(z)}\right.$ hereafter). The range of $\operatorname{IRP}_{(z)}$ at any site is $20-50 \mathrm{~dB}$ : wider ranges are found at sites $B, C$ and $F$ (Fig. 5). At these sites, a thick zone with a large difference of approximately $10-20 \mathrm{~dB}$ was found in the shallower half to two-thirds of the ice. The radar-reflecting layer was detected in this depth range only on the transverse transects (Fig. 3). However, larger $\operatorname{IRP}_{(z)}$ were observed on the longitudinal transects. It is unlikely that longitudinal inclination of the layer (less than several degrees; Fig. 3) causes a difference of 10-20 dB between echo intensities on longitudinal and transverse transects. Thus, the radarreflecting layer is not responsible for differences in $\operatorname{IRP}_{(z)}$ between radar transects.

\section{CAUSES OF ECHO-INTENSITY VARIATIONS}

Apparent variations in the radio-echo intensity can be caused by small changes in antenna-coupling effects due to the transient water content of surface snow (Arcone, 1995;

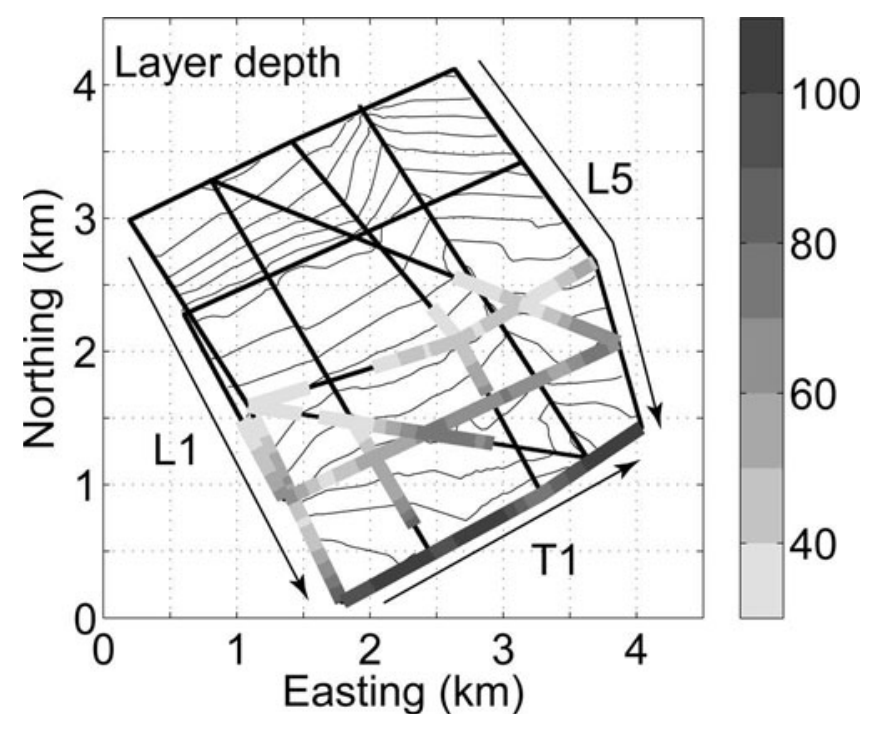

Fig. 3. Depth variations of the radar-reflecting layer. The grayscale represents depth in meters. Sections of tracks where no layer was detected are plotted with narrower lines. Background contours show the glacier surface elevation with $10 \mathrm{~m}$ intervals. 
Table 1. Echo intensity, $\overline{\mathrm{IRP}}_{\mathrm{s}}$, averaged over the full ice thickness at six radar-transect crossover sites (Fig. 4). Values in parentheses express a ratio relative to $\overline{I R P}_{\mathrm{S}}$ on the longitudinal transects $\left(=10 \log \overline{\operatorname{IRP}}_{\mathrm{S} \text { (transverse/oblique) }} / \overline{\mathrm{IRP}}_{\mathrm{S}(\text { Iongitudinal) (transverse/oblique) })}\right.$

\begin{tabular}{lccl} 
Site & & \multicolumn{1}{c}{${\overline{\mathbb{R P}_{\mathrm{s}}}}$} & \\
& Oblique & \multicolumn{1}{c}{ Transverse } \\
\hline $\mathrm{A}$ & 1.23 & $1.26(0.1 \mathrm{~dB})$ & $0.31(-6.0 \mathrm{~dB})$ \\
$\mathrm{B}$ & 5.37 & & $0.11(-16.9 \mathrm{~dB})$ \\
$\mathrm{C}$ & 5.08 & & $0.19(-14.3 \mathrm{~dB})$ \\
$\mathrm{D}$ & 1.44 & & $0.52(-4.4 \mathrm{~dB})$ \\
E & 6.32 & $7.42(0.7 \mathrm{~dB})$ & \\
F & 8.14 & & $0.70(-10.6 \mathrm{~dB})$ \\
\end{tabular}

Gades, 1998), temporal variations in the englacial water regimes (Irvine-Fynn and others, 2006) and/or rotation of the radar-polarization plane (Walford and others, 1986). Transients in the antenna coupling are unlikely to cause the ratios between the echo intensities for the longitudinal and transverse transects to vary significantly with depth (Fig. 5). Irvine-Fynn and others (2006) reported significant temporal variations in the englacial radio echoes from a Canadian glacier over approximately 6 weeks, from late June to early August. Our radar survey was carried out over 3 days; we profiled T1 and T3 between $1550 \mathrm{~h}$ and $1754 \mathrm{~h}$ on 19 April, and L4, L3 and T2 sequentially from $1347 \mathrm{~h}$ to $1542 \mathrm{~h}$ on 20 April. Therefore, we can attribute variations in $\overline{\mathrm{IRP}}_{\mathrm{s}}$ and $\operatorname{IRP}_{(z)}$ at the radar-transect crossover sites to variations in the polarization-plane azimuth.

The observed range of $10-20 \mathrm{~dB}$ in $\operatorname{IRP}_{(z)}$ variations in terms of the polarization-plane azimuth is much larger than the previously reported value $(0.7 \mathrm{~dB})$ obtained by Walford and others (1986) in temperate ice with $60 \mathrm{MHz}$ radar. Possible causes of anisotropy in the echo are azimuthal dependencies of backscattering from englacial targets and/or of forward scattering along the propagation paths and/or birefringence related to the principal axes of the ice fabric along the propagation path. The angles between the longitudinal and transverse radar transects at sites B, C and $\mathrm{F}$ range between $79^{\circ}$ and $90^{\circ}$. Birefringence is less likely to be responsible for the variations found with nearly orthogonal polarization planes, because birefringence produces $90^{\circ}$ periodicity in echo intensity in terms of the polarizationplane azimuth (Matsuoka and others, 2003). Therefore, we conclude that the apparent variations in the echo intensity at radar-transect crossover sites are caused by anisotropic scattering.

The observed anisotropy is found over a depth range of more than $100 \mathrm{~m}$. As the wavelength of the radio wave used for this measurement is $33.7 \mathrm{~m}$ in ice, we assume multiple scatterers are responsible for the observed anisotropy. Furthermore, the anisotropy is found at similar depths at sites B, C and F, which are $1.4 \mathrm{~km}$ apart (Figs 4 and 5). This implies that the anisotropic scattering is probably caused by horizontal scatterers rather than by vertical scatterers. Horizontal scatterers were found in several direct measurements and radar surveys (Holmlund, 1988; Arcone and Yankielun, 2000; Stuart and others, 2003). We conclude that observed anisotropy in the echo is more likely to be caused by backscattering than by forward scattering, since anisotropy in

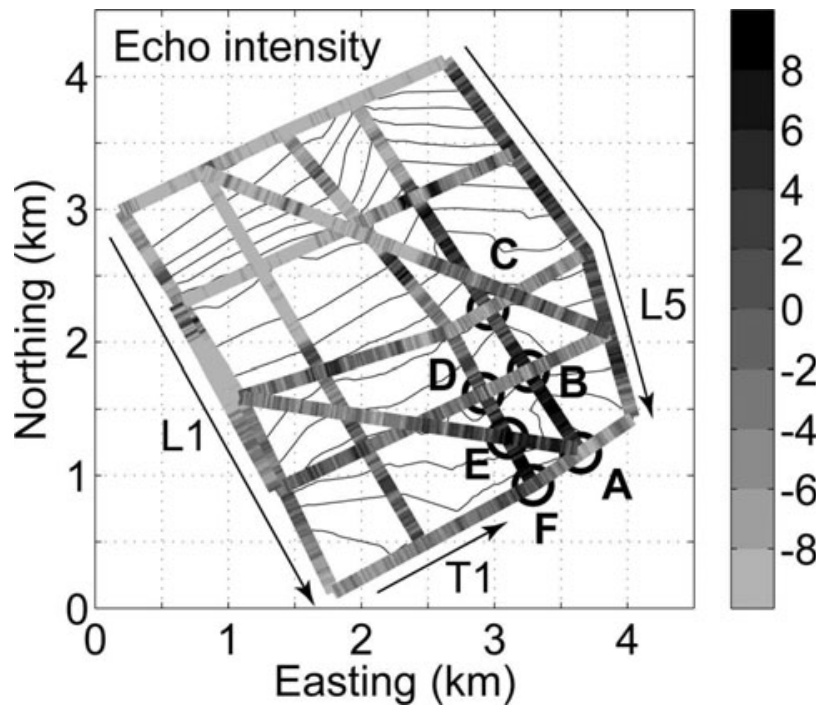

Fig. 4. Depth-averaged englacial received power, $\overline{\mathrm{IRP}}_{\mathrm{s}}$, along the transects in $\mathrm{dB}$ shown with a grayscale. Circles with labels $\mathrm{A}-\mathrm{F}$ show the radar-transect crossover sites where large azimuthal differences were found in $\overline{\mathrm{IRP}}_{\mathrm{S}}$ (Table 1). Sites A, B and C are on L4 and the other three sites are on L3. Contours show the glacier surface elevation with $10 \mathrm{~m}$ intervals.

forward scattering at a shallower depth does not solely explain depth-dependent anisotropy observed at greater depths (Fig. 5). No other constraints on the shape of the water passageways are available in this study area.

To interpret the measured variations in $\operatorname{IRP}_{(z)}$, we examined backscattering characteristics of an infinitely long, circular cylinder parallel to the glacier surface (Bohren and Huffman, 1983, p. 194) as a possible water passageway. The radar data suggest that there are multiple scatterers, but this dataset with a single frequency and only two orthogonal polarizations is insufficient to constrain the geometry of multiple scatterers. So, as a first step, we assume a single cylinder to examine the range and azimuthal pattern of the observed echo. For a given depth, azimuthal variations of $\operatorname{IRP}_{(z)}$ are the same as those of backscattering cross-section, defined as the ratio of the scattered radio-wave intensity to the incident intensity, and can be calculated using amplitude scattering matrices (Bohren and Huffman, 1983). The crosssection, $\sigma$, of a cylinder in ice is a function of the dielectric permittivity of the material (air or water) in the cylinder, the cylinder diameter, $a$, and the angle, $\theta$, between the cylinder axis and the polarization plane.

If the cylinder axis is aligned with one of the polarizationplane azimuths, the observed range of $I R P_{(z)}$ can be given by the azimuthal range, $|\delta \sigma|$, of the backscattering crosssection, which is $\sigma$ normalized with its value parallel to the cylinder $\left(\theta=0^{\circ}\right)$ such that

$$
|\delta \sigma|=|\sigma(a, \theta) / \sigma(a, 0)| \text {. }
$$

In our measurements, $\theta$ ranges from $79^{\circ}$ to $90^{\circ}$. If the cylinder axis is not aligned with the polarization-plane azimuth, the observed range of $\operatorname{IRP}_{(z)}$ is smaller than $|\delta \sigma|$. Figure 6 shows the range of $\left|\delta \sigma_{\text {(air) }}\right|$ and $\left|\delta \sigma_{\text {(water) }}\right|$, respectively, for an air-filled and a water-filled cylinder; $\left|\delta \sigma_{(\text {air })}\right|$ is $<10 \mathrm{~dB}$ for a cylinder diameter $<10 \mathrm{~m}$, while $\left|\delta \sigma_{\text {(water) }}\right|$ can be $>20 \mathrm{~dB}$ for any diameter $<4.8 \mathrm{~m}$ for $\theta=80^{\circ}$.

Besides the range, water-filled and air-filled cylinders make an opposite azimuthal pattern of the scattering; a 


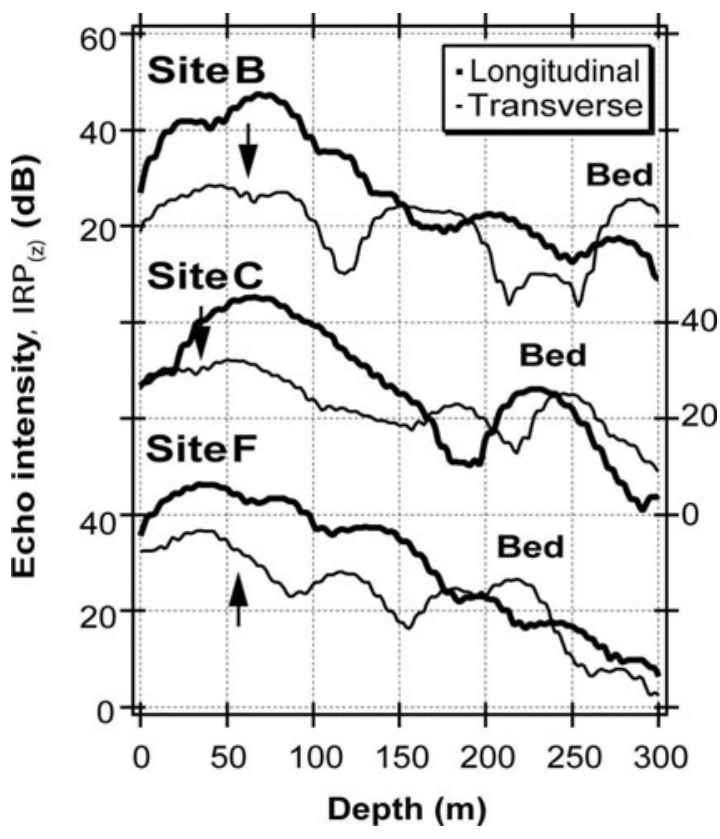

Fig. 5. Depth variations of the received power, $I R P_{(z)}$, at radartransect crossover sites (Fig. 4). Thick and thin curves show IRP $(\mathrm{z})$ for longitudinal and transverse radar transects, respectively. The radarreflecting layer was identified only on transverse transects at these sites, at depths indicated with arrows. Scales for sites B and F are shown on the left, while the scale for site $C$ is shown on the right.

water-filled cylinder gives strongest scattering when the radar polarization plane is parallel to the cylinder axis, while an air-filled cylinder scatters most strongly when the radar polarization is perpendicular to the cylinder axis. The azimuthal pattern depends on the ratio of the cylinder diameter to the radio-wave wavelength, and on the relative magnitudes of permittivities of the scatterer and the medium. These dependencies of the azimuthal pattern have been used to optimize polarization used to characterize buried targets in ground-penetrating radar applications (Daniels and others, 1988; Radzevicius and Daniels, 2000). In our case, this azimuthal pattern for the air-filled cylinder holds for a cylinder where the diameter is less than $\sim 40 \mathrm{~m}$ at the radar frequency of $5 \mathrm{MHz}$. This result suggests that the observed variations of $\operatorname{IRP}_{(z)}$ with azimuth relative to the polarization plane can be caused by water-filled longitudinal horizontal cylindrical structures within the ice.

Our $5 \mathrm{MHz}$ radar does not readily resolve individual, distinct water passageways, unlike the $100 \mathrm{MHz}$ radar used by Arcone and Yankielun (2000) for a temperate glacier and by Stuart and others (2003) for a cold glacier. The wavelengths of the 5 and $100 \mathrm{MHz}$ radio wave are 33 and $1.7 \mathrm{~m}$ in ice, respectively. Radiation patterns of the antenna for higher frequencies are, in general, sharper. Thus, our $5 \mathrm{MHz}$ radar illuminates a wider area simultaneously but with a lower resolution than the $100 \mathrm{MHz}$ radar. The glacier interior is probably too complex to allow individual water passageways to be identified using $5 \mathrm{MHz}$ radar. This suggests that the depth-dependent azimuthal variations obtained using the $5 \mathrm{MHz}$ radar are caused by an ensemble of water passageways.

Radio waves of $1-10 \mathrm{MHz}$ are commonly used for temperate glaciers to ensure penetration. However, resolution is poor and thus delineation of individual water passageways is not feasible. Our field data indicate that

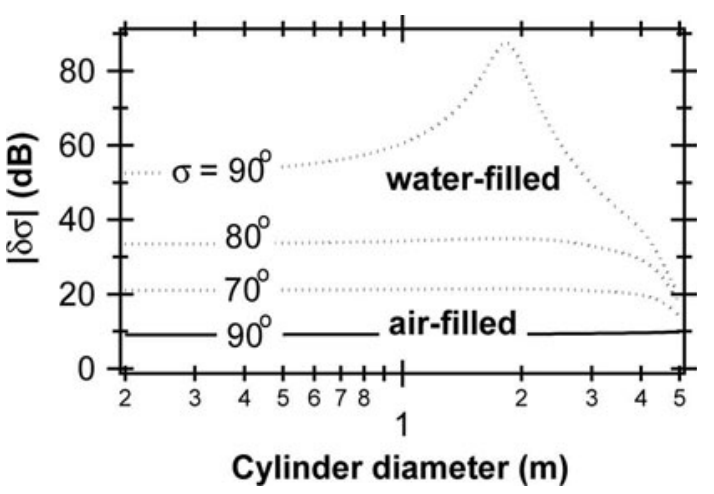

Fig. 6. The range of backscattering cross-section, $|\delta \sigma|$ (Equation (2)), at the radar frequency of $5 \mathrm{MHz}$ for an air-filled (solid curve) and a water-filled (dashed curve) cylinder. For a water-filled cylinder, $|\delta \sigma|$ for the azimuths of $80^{\circ}$ and $70^{\circ}$ are also shown.

ensembles of water passageways, rather than individual passages, can return polarized, depth-dependent echoes. This implies that polarimetric radar observations at low frequencies $(\sim \mathrm{MHz})$ can potentially constrain statistical characteristics of water-passageway ensembles such as azimuth, slope, shape and dimensions in complicated interiors of temperate glaciers.

\section{CONCLUSIONS AND OUTLOOK}

Our $5 \mathrm{MHz}$ radar survey at a temperate glacier, Mýrdalsjökull, showed that the depth-averaged echo intensity from within the ice varies with the polarization-plane azimuth by up to $17 \mathrm{~dB}$. The echo intensity at a given depth varies with the polarization-plane azimuth by $10-20 \mathrm{~dB}$. This is consistent with the azimuthal pattern and the range of variation expected for a water-filled longitudinal horizontal cylinder. We conclude that large, water-related scattering causes apparent discontinuities in the radar-reflecting layer at some polarizations. The polarization-dependent feature found here suggests that greater attention should be given to selection of the polarization plane in radar sounding. Radar profiling along several transects crossing obliquely will help clarify whether a layer disappears or if scattering arising from water passageways masks the layer.

Careful measurements using low-frequency $(\sim \mathrm{MHz})$ radar can detect variations in the radio-echo intensity in terms of the azimuth of the polarization plane. Although they cannot characterize individual water passageways because of their long wavelengths, statistical characteristics of ensembles of water passageways can potentially be obtained. To establish observational strategies and analytical algorithms to investigate water passageways, it is crucial to conduct theoretical and laboratory studies of the polarization dependence, as well as the frequency dependence, on the scattering from ensembles of water passageways including both conduits and fractures. Knowledge of radio-wave propagation through curved scatterers will also contribute to better understanding of the bed and sedimentary inclusions near the bottom of temperate glaciers and ice streams.

\section{ACKNOWLEDGEMENTS}

I. Howat, S. O'Neel, B. Oddsson, G. Á. Gíslason and P.M. Sveinsson helped with the radar measurements. 
Logistic support from B. Bragason at Arcanum is greatly appreciated. We thank S. Arcone, J. Woodward and Scientific Editor B. Hubbard, for careful and constructive reviews. This research was supported by US National Science Foundation grants OPP-0136112, OPP-0136141 and ARC0520541.

\section{REFERENCES}

Arcone, S.A. 1995. Numerical studies of the radiation patterns of resistively loaded dipoles. J. Appl. Geophys., 33(1-3), 39-52.

Arcone, S.A. and N.E. Yankielun. 2000. 1.4 GHz radar penetration and evidence of drainage structures in temperate ice: Black Rapids Glacier, Alaska, USA. J. Glaciol., 46(154), 477-490.

Bamber, J.L. 1987. Internal reflecting horizons in Spitsbergen glaciers. Ann. Glaciol., 9, 5-10.

Björnsson, $\mathrm{H}$. and 6 others. 1996. The thermal regime of sub-polar glaciers mapped by multi-frequency radio-echo sounding. J. Glaciol., 42(140), 23-32.

Björnsson, H., F. Pálsson and M.T. Guðmundsson. 2000. Surface and bedrock topography of Mýrdalsjökull, Iceland: the Katla caldera, eruption sites and routes of jökulhlaups. Jökull, 49, 29-46.

Bohren, C.F. and D.R. Huffman. 1983. Absorption and scattering of light by small particles. New York, John Wiley and Sons.

Brandt, O., H. Björnsson and Y. Gjessing. 2005. Mass-balance rates derived by mapping internal tephra layers in Mýrdalsjökull and Vatnajökull ice caps, Iceland. Ann. Glaciol., 42, 284-290.

Catania, G.A., H.B. Conway, A.M. Gades, C.F. Raymond and H. Engelhardt. 2003. Bed reflectivity beneath inactive ice streams in West Antarctica. Ann. Glaciol., 36, 287-291.

Daniels, D.J., D.J. Gunton and H.E. Scott. 1988. Introduction to subsurface radar. IEE Proc. F, 135(4), 278-320.

Fountain, A.G. and J.S. Walder. 1998. Water flow through temperate glaciers. Rev. Geophys., 36(3), 299-328.

Fountain, A.G., R.W. Jacobel, R. Schlichting and P. Jansson. 2005. Fractures as the main pathways of water flow in temperate glaciers. Nature, 433(7026), 618-621.

Gades, A.M. 1998. Spatial and temporal variations of basal conditions beneath glaciers and ice sheets inferred from radio echo soundings. (PhD thesis, University of Washington.)

Gades, A.M., C.F. Raymond, H. Conway and R.W. Jacobel. 2000. Bed properties of Siple Dome and adjacent ice streams, West
Antarctica, inferred from radio-echo sounding measurements. J. Glaciol., 46(152), 88-94.

Holmlund, P. 1988. Internal geometry and evolution of moulins, Storglaciären, Sweden. J. Glaciol., 34(117), 242-248.

Irvine-Fynn, T.D.L., B.J. Moorman, J.L.M. Williams and F.S.A. Walter. 2006. Seasonal changes in ground-penetrating radar signature observed at a polythermal glacier, Bylot Island, Canada. Earth Surf. Process. Landf., 31(7), 892-909.

Jacobel, R. and C. Raymond. 1984. Radio-echo-sounding studies of englacial water movement in Variegated Glacier, Alaska. J. Glaciol., 30(104), 22-29.

Matsuoka, K. and 6 others. 2003. Crystal-orientation fabrics within the Antarctic ice sheet revealed by a multi-polarization-plane and dual frequency radar survey. J. Geophys. Res., 108(B10), 2499. (10.1029/2002JB002425.)

Matsuoka, K., R. Saito and R. Naruse. 2004. A novel backpackable ice-penetrating radar system. J. Glaciol., 50(168), 147-150.

Moore, J.C. and 8 others. 1999. High-resolution hydrothermal structure of Hansbreen, Spitsbergen, mapped by groundpenetrating radar. J. Glaciol., 45(151), 524-532.

Pettersson, R. 2005. Frequency dependence of scattering from the cold-temperate transition surface in a polythermal glacier. Radio Sci., 40(3), RS3007. (10.1029/2004RS003090.)

Radzevicius, S.J. and J.J. Daniels. 2000. Ground penetrating radar polarization and scattering from cylinders. J. Appl. Geophys. 45(2), 111-125.

Shreve, R.L. 1972. Movement of water in glaciers. J. Glaciol., 11(62), 205-214.

Stuart, G., T. Murray, N. Gamble, K. Hayes and A. Hodson. 2003. Characterization of englacial channels by ground-penetrating radar: an example from austre Brøggerbreen, Svalbard. J. Geophys. Res., 108(B11), 2525. (10.1029/2003JB002435.)

Thorsteinsson, T., E.D. Waddington, K. Matsuoka, I. Howat and S. Tulaczyk. 2005. Survey of flow, topography and ablation on NW-Mýrdalsjökull, S-Iceland. Jökull, 55, 155-162.

Walford, M.E.R., M.I. Kennett and P. Holmlund. 1986. Interpretation of radio echoes from Storglaciären, northern Sweden. J. Glaciol., 32(110), 39-49.

Weertman, B.R. 1993. Interpretation of ice sheet stratigraphy: a radio-echo sounding study of the Dyer Plateau, Antarctica. (PhD thesis, University of Washington.)

Zwally, H.J., W. Abdalati, T. Herring, K. Larson, J. Saba and K. Steffen. 2002. Surface melt-induced acceleration of Greenland icesheet flow. Science, 297(5579), 218-222. 